\title{
Non-Steroidal Anti-Inflammatory Drug Use Reduces Risk for Adenocarcinomas of the Esophagus and Esophagogastric Junction in a Pooled Analysis
}

\author{
Linda M. Liao', Thomas L. Vaughan², Douglas A. Corley ${ }^{3}$, Michael B. Cook ${ }^{1}$, Alan G. \\ Casson $^{4}$, Farin Kamangar ${ }^{1,5}$, Christian C. Abnet ${ }^{1}$, Harvey A. Risch ${ }^{6}$, Carol Giffen ${ }^{7}$, Neal D. \\ Freedman ${ }^{1}$, Wong-Ho Chow ${ }^{1}$, Shahram Sadeghi ${ }^{8}$, Nirmala Pandeya ${ }^{8}$, David C. Whiteman ${ }^{8}$, \\ Liam J. Murray ${ }^{9}$, Leslie Bernstein ${ }^{10}$, Marilie D. Gammon ${ }^{11}$, and Anna H. Wu ${ }^{12}$
}

${ }^{1}$ Division of Cancer Epidemiology and Genetics, National Cancer Institute, National Institutes of Health, Bethesda, MD ${ }^{2}$ Epidemiology Program, Fred Hutchinson Cancer Research Center, Seattle, WA ${ }^{3}$ Division of Research and Oakland Medical Center, Kaiser Permanente, Northern California, Oakland, CA ${ }^{4}$ Department of Surgery, University of Saskatchewan, Saskatoon, SK, Canada ${ }^{5}$ Department of Public Analysis, School of Community Health and Policy, Morgan State University, Baltimore, MD ${ }^{6}$ Department of Epidemiology and Public Health, Yale University School of Medicine, New Haven, CT ${ }^{7}$ Information Management Services, Silver Spring, MD ${ }^{8}$ Division of Genetics and Population Health, Queensland Institute of Medical Research, Brisbane, Queensland, Australia ${ }^{9}$ Cancer Epidemiology and Health Services Research, Centre for Public Health, Queen's University, Belfast, Northern Ireland ${ }^{10}$ Division of Cancer Etiology, Department of Population Sciences, Beckman Research Institute, City of Hope, Duarte, CA ${ }^{11}$ Department of Epidemiology, University of North Carolina School of Public Health, Chapel Hill, NC ${ }^{12}$ Department of Preventive Medicine, Keck School of Medicine, USC Norris Comprehensive Cancer Center, Los Angeles, CA

\section{Abstract}

Background \& Aims-Regular use of aspirin and other non-steroidal anti-inflammatory drugs (NSAID) has been reported to reduce risks for esophageal adenocarcinoma (EAC) and esophagogastric junctional adenocarcinoma (EGJA). However, individual studies have been too small to accurately assess the effects of medication type, frequency, or duration of use. We performed a pooled analysis to investigate these associations.

Methods-We performed a pooled analysis of 6 population-based studies within the Barrett's and Esophageal Adenocarcinoma Consortium to evaluate the association between NSAID use and

(C) 2011 The American Gastroenterological Association. Published by Elsevier Inc.

Correspondence: Linda M. Liao, PhD, Occupational and Environmental Epidemiology Branch, Division of Cancer Epidemiology and Genetics, National Cancer Institute, National Institutes of Health, 6120 Executive Blvd, EPS/Rm 8003, Bethesda, MD 20852, liaolm@mail.nih.gov; phone: 301-451-5034; fax: 301-402-1819.

Disclosures: No conflicts of interest exist.

Author Contributions: TLV, DAC, AGC, CCA, HAR, WHC, DCW, LJM, LB, MDG, and AHW organized and designed the BEACON consortium. TLV, DAC, AGC, CCA, HAR, WHC, DCW, LJM, LB, MDG, and AHW conducted the epidemiologic studies and contributed data to the pooled analysis. LML, TLV and AHW contributed to the analysis and interpretation of data. LML conducted the statistical analysis and wrote the first draft of the manuscript. CG provided data management and support. All authors contributed to critical revision of the manuscript for important intellectual content.

Publisher's Disclaimer: This is a PDF file of an unedited manuscript that has been accepted for publication. As a service to our customers we are providing this early version of the manuscript. The manuscript will undergo copyediting, typesetting, and review of the resulting proof before it is published in its final citable form. Please note that during the production process errors may be discovered which could affect the content, and all legal disclaimersthat apply to the journal pertain. 
the risk of EAC and EGJA, using uniform exposure definitions. We collected information from 6 studies (5 case-control and 1 cohort), with a total of 1226 EAC and 1140 EGJA cases, on aspirin and/or NSAID use. Study-specific odds ratios (ORs) and 95\% confidence intervals (CIs) were estimated using multivariate adjusted logistic regression models and then pooled using a random effects meta-analysis model.

Results-Compared to non-users, individuals who have used NSAIDs had a statistically significant, reduced risk of EAC $(\mathrm{OR}=0.68 ; 95 \% \mathrm{CI}, 0.56-0.82)$; they also appeared to have a reduced risk of EGJA (OR=0.84; 95\% CI, 0.68-1.03). Similar reductions in risk were observed among individuals who took aspirin or non-aspirin NSAIDs. The highest levels of frequency ( $\geq$ daily) and duration ( $\geq 10$ years) of NSAID use were associated with an approximately $40 \%$ reduction in risk for EAC: $\mathrm{OR}=0.56(95 \% \mathrm{CI}, 0.43-0.73 ; P$-trend, <.001) and $\mathrm{OR}=0.63(95 \% \mathrm{CI}$, $0.45-0.90 ; P$-trend, 0.04), respectively.

Conclusions-Although reverse causation could, in part, explain the inverse association observed between NSAID use and EAC risk, pooled analysis indicates a role for NSAIDs in prevention of adenocarcinomas of the esophagus and esophagogastric junction.

\section{Keywords}

BEACON; Esophageal Neoplasm; Stomach Cancer; Anti-Inflammatory Agent

\section{Introduction}

The incidence of esophageal adenocarcinoma (EAC) has increased considerably in many Western countries over the past three decades ${ }^{1,2}$. The disease continues to have a very low survival rate ${ }^{3}$. Esophagogastric junctional adenocarcinomas (EGJA) are a heterogeneous group of adenocarcinomas which reside within the gastric cardia and/or the gastroesophageal junction. Similar to EAC, upward trends of EGJA have been reported in Western countries in recent years ${ }^{4,5}$.

Inflammation, caused by factors such as gastroesophageal reflux, is believed to cause EGJA and EAC, suggesting a plausible preventative role for anti-inflammatory agents. A primary preventive mechanism for non-steroidal anti-inflammatory drugs (NSAIDs) is thought to be the inhibition of cyclooxygenase-2 (COX-2) production, an enzyme that is an important mediator of inflammation ${ }^{6,7}$. Elevated COX-2 expression has been observed in Barrett's esophagus, a precursor lesion of EAC, with expression levels noted to increase with disease progression to $\mathrm{EAC}^{8,9}$. Experimental studies have also shown that treatment with $\mathrm{COX}-2$ inhibitors can inhibit the growth in vitro of Barrett's esophagus cells, an effect potentially mediated by suppression of basic fibroblast growth factor ${ }^{10-12}$. Higher levels of COX-2 expression also have been detected in gastric carcinomas ${ }^{13}$. Although several studies have observed that COX-2 inhibitors slow the growth of gastric tumor cells and induce apoptosis, they have also suggested that this may be mediated through pathways other than suppressing COX $-2^{14,15}$.

Frequent use of NSAIDs has been associated with a reduced risk of gastrointestinal cancers in many epidemiologic studies 16,17 . Studies conducted thus far on NSAID use have focused mainly on colorectal cancer, with a smaller but growing number of studies investigating NSAID use in relation to esophageal and gastric cancers. The majority of these studies support an inverse association between NSAID use and risk of EAC and EGJA 18-26. Previous reviews have largely limited their evaluations of NSAID use and risk of EAC and EGJA to assessments of ever- use ${ }^{27-31}$. It is not known whether specific characteristics of NSAID use, such as frequency or duration of use, are important in reducing the risks of specific subtypes of these cancers. 
The Barrett's and Esophageal Adenocarcinoma Consortium (BEACON) was established in 2005 in part to assemble a large sample size of well-characterized patients with esophageal adenocarcinoma or Barrett's esophagus and representative controls, which would allow us to better define risk factors of Barrett's esophagus and adenocarcinomas of the esophagus and gastroesophageal junction ${ }^{32}$. We performed a pooled analysis of studies within the BEACON consortium, after harmonization of variables using individual-level data, to comprehensively evaluate the association between aspirin and NSAID use and the risk of EAC and EGJA.

\section{Materials and Methods}

\section{Study Populations}

Among the twelve BEACON studies, we identified six with sufficient information on aspirin and non-aspirin NSAID use to contribute to the pooled analyses of EAC (Table 1). Five studies were population-based case-control studies: the Australian Study of Esophageal Cancer ${ }^{33}$, the Nova Scotia Barrett Esophagus Study ${ }^{34}$, the United States Multi-center Study ${ }^{24}$, the Factors Influencing the Barrett's Adenocarcinoma Relationship Study ${ }^{20}$, and the Los Angeles County Multi-Ethnic Study ${ }^{35}$; and one was a cohort study: the National Institutes of Health-AARP (NIH-AARP) Diet and Health Study ${ }^{29}$. The NIH-AARP cohort study provided data on all eligible cases and a random subset of controls (4:1) from among cohort members with follow-up through 2003. Data acquired and data pooling for each study was approved by the institutional review board or research ethics committee of the institute sponsoring the study.

Since cancers that arise from the cardia of the stomach and the gastroesophageal junction present distinct features in comparison with cancers from the distal portion of the stomach, we have chosen to define adenocarcinomas of the gastric cardia and gastroesophageal junction as EGJA in this analysis. Our analysis was restricted to Caucasians as there were few non-Caucasian case subjects ( $n=75$ EAC, $n=96$ EGJA) among the studies with available information on NSAIDs. The six studies contributed data on a total of 1226 EAC cases, 1140 EGJA cases, and 5314 controls.

\section{Exposure variables}

For this analysis, the main exposures of interest were the use of aspirin, non-aspirin NSAIDs, and all NSAIDs (aspirin and non-aspirin NSAIDs combined). The questionnaires from each study were reviewed and all questions that assessed the use of individual NSAIDs -- aspirin and other non-aspirin NSAIDs -- and overall NSAIDs were extracted. Questions from each study were asked in various formats (both open-ended and predefined responses) and ranged from a simple yes/no question to more detailed questions regarding frequency and duration of use of specific drugs (Appendix A). Data were then formatted to create a uniform exposure suitable for pooling and estimating effects of each exposure. Category cutpoints for both frequency and duration were chosen based on the literature and after evaluating how each study categorized these variables in their original data. Each exposure was evaluated and categorized, as follows: ever (subdivided into current and former, when possible) versus non-use, frequency of use (non-use, 0.1 to $<1 /$ week, $\geq 1$ to $<7 /$ week, $\geq 7 /$ week), and duration of use (non-use, 0.1 to $<5$ years, $\geq 5$ to $<10$ years, $\geq 10$ years). Participants categorized as having "Non-use" were those who indicated "no" or "never" to any questions regarding their NSAID use (Appendix A). "Current use" was defined as individuals who continued to take the drugs as of the interview date, or indicated that the age or calendar year that they stopped taking the drugs was within a year of the interview date. If the number of cases in a category was too small in the pooled dataset, the category was collapsed together with a neighboring category. Determination of overall NSAID frequency 
and duration was calculated by combining information from both aspirin and non-aspirin NSAID use when available. If the questionnaire did not differentiate between the two types of NSAIDS and only asked questions on overall NSAID use, these values were then used for estimates of overall NSAID frequency and duration. For duration of overall NSAID use, we summed years of aspirin use and non-aspirin NSAID use. For frequency of overall NSAID use, we calculated a combined frequency that was weighted by the duration of aspirin use and non-aspirin NSAID use $\left(\mathrm{NSAID}_{\text {freq }}=\left[\left(\right.\right.\right.$ Asprin $_{\text {freq }}{ }^{*}$ Asprin $\left._{\text {duration }}\right)+($ Non-aspirin

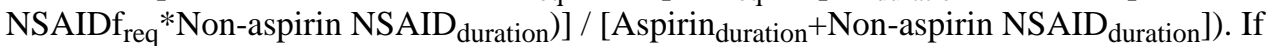
information on frequency was recorded in categories, we assigned the median of each previously defined category as the value for that specific category. Actual amount or dosage for NSAID use was not available from any of the study questionnaires.

A major advantage of having access to the individual patient data from each study is that similar study-specific analytic models can be built, thus increasing the validity of their combination using a meta-analytic model. Additional variables that were acquired from each study and considered as covariates for this analysis included: age, sex, body mass index (BMI: $\mathrm{kg} / \mathrm{m}^{2}$ ), gastroesophageal reflux status (ever versus no), education, smoking exposure (pack-years), alcohol intake (drinks per day) and study center. Age was defined as age at diagnosis for cases, age at interview for controls from case-control studies, and age at baseline for participants from cohort studies. BMI was calculated by dividing weight $(\mathrm{kg})$ by the square of height (m). Gastroesophageal reflux status was missing in two studies ${ }^{29,34}$. A study-specific education variable was used in analyses as a different method of categorization was employed in each study. Smoking exposure was characterized by packyears of tobacco exposure (number of cigarettes smoked per day x number of years smoked / 20) and has been previously described ${ }^{32}$. Alcohol intake was measured as the average frequency of alcohol consumption ${ }^{36}$.

\section{Statistical Analysis}

The analyses were conducted in two stages. We first used unconditional logistic regression to calculate study-specific estimates of odds ratios (OR) and 95\% confidence intervals (95\% $\mathrm{CI}$ ), adjusted for age (categorical: $\langle 50,50-59,60-69, \geq 70$ years), sex, BMI (categorical: $<25,25-29.9, \geq 30 \mathrm{~kg} / \mathrm{m}^{2}$ ), gastroesophageal reflux (ever versus no, where available), education (study specific), smoking exposure (categorical: $0,<15,15-29,30-44, \geq 45$ packyears), alcohol intake (categorical: 0,1-1.9, 2-2.9, 3 drinks per day) and study center (applicable for multicenter studies only). Additional adjustment for antacid use (yes versus no) had minimal effect on the study-specific and pooled summary estimates so it was not included in the final model. In all analyses of aspirin and non-aspirin NSAID use, mutual adjustment for any use of the other type of NSAID was included in each respective model. This allowed us to observe an effect that accounts for any contribution from the other type of NSAID. Tests for trends were calculated by modeling exposures as ordinal variables in multivariate models. In the second stage, we performed a pooled analysis combining studyspecific ORs using a random-effects meta-analytic model to calculate a summary OR. Each summary OR represents data from only the specific studies that contributed to that exposure category, thus a study would be excluded from an analysis if it did not generate a stable OR.

\section{Evaluation of heterogeneity and effect modification}

The amount of total variation among studies due to heterogeneity was assessed using the $P^{2}$ statistic ${ }^{37}$. Larger $I^{2}$ values could reflect greater heterogeneity between the study-specific estimates, beyond what is attributable to chance. We evaluated for potential sources of heterogeneity using stratified analyses by levels of exposure, gastroesophageal reflux symptoms, method of evaluating exposure (i.e. type of question) and levels of potential confounders. To evaluate whether other variables modified the effect of NSAID use on 
cancer risk, we conducted analyses stratified by BMI $\left(<25 \mathrm{~kg} / \mathrm{m}^{2}, \geq 25 \mathrm{~kg} / \mathrm{m}^{2}\right)$, smoking status (never vs. ever), sex, gastroesophageal reflux, age ( $<60$ years, $\geq 60$ years), and education (high school or less, $>$ high school). All analyses were performed using STATA software, version 10.0 (StataCorp LP, College Station, TX).

\section{Results}

The included studies are described in Table 1. The mean age of EAC cases, EGJA cases and controls was 63.7 years, 63.1 years and 61.7 years, respectively. A large majority of cases (EAC: $88.4 \%$, EGJA: $85.8 \%$ ) and controls $(68.1 \%)$ were male. The overall prevalence of ever NSAID use among controls was $69 \%$, which varied between studies from $37 \%$ to $87 \%$. Overall, the proportion of persons reporting ever using NSAIDs was $56.6 \%$ among EAC cases and 59.6\% among EGJA cases compared to $68.6 \%$ among controls.

\section{Overall NSAID use}

Compared to non-use, ever use of any NSAID was statistically significantly associated with a reduced risk of EAC $(\mathrm{OR}=0.68,95 \% \mathrm{CI}=0.56-0.82$; Table 2; Supplementary Figure 1). Ever use of NSAIDs was inversely, but not statistically significantly, associated with risk of EGJA. Furthermore, these associations appeared to be restricted to current users of NSAIDs. Decreasing risk of EAC was observed with increasing frequency of overall NSAID use. Occasional use of NSAIDs was associated with an OR of 0.66 (95\% CI=0.43-1.00) and daily or greater use was associated with an $\mathrm{OR}$ of 0.56 (95\% CI=0.43-0.73; p-trend<0.001). NSAID use for any duration also appeared to be associated with a reduced risk of EAC, but a trend of decreasing risk with increased duration was not seen. We found no evidence of a relationship between increased frequency or duration of NSAID use and risk of EGJA.

\section{Aspirin Use}

Five studies collected information on aspirin use. Ever use of aspirin was associated with a statistically significant $24 \%$ decreased risk of EAC $(95 \% \mathrm{CI}=3-40 \%)$ and a $16 \%$ decreased risk of EGJA (95\% CI= 0-31\%) compared to non-use (Table 3). The inverse association with aspirin use and risk of both outcomes appeared to be limited to current use. We observed a suggestive trend of decreasing risk of EAC associated with increasing frequency of aspirin use (p-trend=0.03; Supplementary Figure 3), but there was no apparent trend with increasing duration of aspirin use ( $\mathrm{p}$-trend=0.57). Increased frequency or duration of aspirin use was not statistically significantly associated with risk of EGJA.

\section{Non-aspirin NSAID use}

Use of non-aspirin NSAIDs was collected in five BEACON studies. Overall, ever use of non-aspirin NSAIDS appeared to be statistically significantly associated with a similar reduced risk of both outcomes compared to non-use: $\mathrm{EAC}$ : $\mathrm{OR}=0.79$ (95\% CI=0.66-0.95); and EGJA: $\mathrm{OR}=0.80$ (95\% CI=0.67-0.94; Table 4). Although not statistically significant and based on a small number of cases, this association may be restricted to current users (Table 4). Beyond any use of non-aspirin NSAIDs, we did not observe a clear trend with increasing frequency or duration of non-aspirin NSAID use with risk of EAC or EGJA.

\section{Type of NSAID use}

Among controls who reported using any type of NSAID, 38\% reported use of aspirin only, $22 \%$ reported use of non-aspirin NSAIDs only, and $41 \%$ reported use of both types of NSAIDs. Compared to those who reported no NSAID use, the use of either aspirin only or non-aspirin NSAIDs only appeared to be associated with almost identical reduced risks of EAC (ORs of 0.68 and 0.66), and EGJA (ORs of 0.92 and 0.93 ), respectively (Table 5). 
Individuals who reported use of both types of NSAIDs were not at significantly reduced risk of EAC; however, they had a statistically significant reduced risk of EGJA than those who reported individual use of aspirin or non-aspirin NSAIDs.

We further evaluated the association between ever use of aspirin and other NSAIDs and risk of each outcome through stratified analyses by other variables: BMI, smoking status, sex, gastroesophageal reflux, age, education, and NSAID question type. Risk estimates appeared similar across strata of these potential risk factors (data not shown).

\section{Discussion}

We found that users of NSAIDs, in particular those reporting current use, experienced a statistically significant lower risk of EAC than those who did not use these medications. We also observed statistically significant inverse associations between greater frequency and duration of NSAID use and risk of EAC. When the analysis was examined by type of NSAID, the magnitude of the effect for ever use of aspirin was similar to the effect for ever use of non-aspirin NSAIDs. However, there was little evidence of a dose-response effect when examining type of NSAID by increasing frequency or duration. The patterns and overall inverse association between NSAID and aspirin use and risk of EGJA appear to be similar to EAC but less striking.

An inverse relationship between NSAID use and esophageal and gastric adenocarcinomas has been reported previously in reviews and meta-analyses ${ }^{27-31}$. An important advantage of our pooled study is that we were able to create more standardized categories of exposure using individual-level data from each study and harmonized analytic models with respect to covariates for adjustment of potential confounding; these steps permit more comparable data than is possible using only results from published odds ratios, which utilize different sets of covariates between studies. We also built on past reviews by evaluating additional aspects of NSAID use, such as frequency, duration, and temporal factors, in a larger number of cases and controls than previous reports. In the most recently published meta-analysis, Abnet et al. reported that any aspirin use was inversely associated with EAC and EGJA cancers with summary ORs of 0.64 (95\% CI=0.52-0.79) and 0.82 (95\% CI=0.65-1.04), respectively ${ }^{29}$. Both are similar to the estimates we observed from our pooled study. We consistently observed that the effect of aspirin and NSAID use was slightly weaker for EGJA than EAC. Although only a few reviews evaluated both EAC and EGJA ${ }^{29,} 30$, the summary estimates reported are consistent with our observations of a stronger association with EAC. This is also consistent with past meta-analyses that reported a statistically significant reduced risk for gastric non-cardia cancer with NSAID use but a weaker effect for EGJA 28,31 . Since these meta-analyses were published, one additional prospective study found an inverse association between regular use of aspirin and risk of EGJA ${ }^{26}$. Four additional studies conducted among high-risk cohorts of patients with Barrett's esophagus, two prospective and two retrospective, have also observed evidence of a reduced risk of progression to EAC with NSAID use ${ }^{19,38-40}$. A pooled analysis of three randomized trials of daily aspirin use and at least 5 years of treatment found a delayed but significant reduction in deaths due to EAC and EGJA after 5+ and 10+ years of post-trial follow-up, respectively ${ }^{41}$. Although, a small, short-term trial of celecoxib/placebo among subjects with Barrett's esophagus found no change in the proportion of dysplastic biopsies between the treatment $(200 \mathrm{mg} /$ pill, 2 pills/ day) and placebo group at 48 weeks ${ }^{42}$, almost half of these patients already had dysplasia at study entry; a much larger randomized trial, including adequate numbers of patients without dysplasia, is needed in order to fully explore this hypothesis. A randomized trial of aspirin and proton pump inhibitors among patients with Barrett's esophagus is currently ongoing in the United Kingdom ${ }^{43}$. Results from this trial will assist in the ongoing effort to further examine the relationship between aspirin and the development of EAC. 
In our study, the association with ever use of aspirin and non-aspirin NSAIDs was generally similar for EAC risk. This is in agreement with findings from other reviews that evaluated the effect of NSAIDs by type. All of our analyses were mutually adjusted for the other type of NSAID, which did not change any of the observed associations substantially. This suggests that although similar in effect estimates, both aspirin and non-aspirin NSAID use appear to have an individual effect on EAC risk above and beyond use of the other type of NSAID. That is, exposure to any member of this class of medication further reduces the risk of EAC. The similar effects of aspirin and non-aspirin NSAID use is substantiated further by the nearly identical associations observed between individuals who reported using aspirin only and individuals who reported using non-aspirin NSAIDs only with EAC and EGJA risk. As experimental studies have reported similar pathways and actions of aspirin and other NSAIDs, such as inhibiting COX-2, decreasing inflammation, increasing apoptosis and decreasing proliferation, it seems reasonable that there would be little difference between their effects on EAC or EGJA risk 44,45 .

Frequency of NSAID use appeared to be more strongly associated with a reduction in EAC risk than duration of NSAID use in this analysis. Our analysis found an inverse relationship with increased frequency of NSAID use (p-trend $<0.001$ ), but a consistent reduced risk of EAC with any level of duration. A similarly strong inverse dose-response between frequent NSAID use and esophageal cancer was also reported in the meta-analysis by Corley et al. ${ }^{27}$. None of the previous EAC meta-analyses evaluated the effect of duration of use so we were unable to compare our results with others. Although we observed an association with risk of EAC, we found no significant associations among the highest categories of frequent or longer duration of NSAID use and risk of EGJA. In a meta-analysis by Wang et al., an inverse association with "regular" or frequent use of NSAIDs and gastric cancer was observed; however, there was inadequate evidence to suggest an association with duration of NSAID use in their analysis ${ }^{28}$. The interpretation of results on frequent NSAID use from the Wang et al. meta-analysis, however, is limited due to the inclusion of a mixture of gastric cancer sites and varying definitions of "regular" NSAID use across studies included in their meta-analysis.

Although analyses were limited to a subset of studies, in our study it appears that the reduced risk of EAC and EGJA was restricted to those who reported current use of NSAIDs. Past reviews have not attempted to summarize the effect of current NSAID status on risk of either EAC or EGJA. This is most likely due to the lack of published estimates, whereas we were able to utilize raw data from three of the six BEACON studies to construct this variable. The current NSAID users in our study tended to report frequent NSAID use (median $=\sim 1$ pill/day) and a moderate duration of use (median $=5$ years). A similar pattern with current NSAID status has been observed in the one prospective study of Barrett's esophagus patients. Vaughan et al. ${ }^{19}$ observed that current NSAID use at baseline was associated with a significantly lower risk of EAC, which was stronger in a subset of patients who were deemed to be current users for the full duration of follow-up (median $=5.5$ years).

Results from our study could suggest a possible short-term protective effect of NSAIDs on EAC and EGJA risk as we observed an effect with current users, higher frequency but not longer duration. However, as our pooled analysis consisted primarily of data from casecontrol studies, some of the observed effect could be due to reverse causation. Continued NSAID use can lead to erosive tissue damage in the gastrointestinal tract, which may result in patients with gastroesophageal reflux discontinuing NSAID use. However, the study's supplemental analyses did not support this possibility; a similar effect of aspirin and NSAIDs use and risk of EAC and EGJA was observed among individuals with or without gastroesophageal reflux. In addition, findings from the NIH-AARP study, a prospective cohort included in this analysis, were similar to findings of EGJA risk among case-control 
studies in this analysis. If replicated in further prospective studies and randomized trials, this could have implications on the use of NSAIDs as a potential preventative measure.

Our pooled study has a number of strengths as well as limitations. It included and combined data from six population-based case-control and cohort studies. This allowed for a large sample size and suitable statistical power to evaluate overall main effect associations, though the case numbers were still small in some strata and limited our power to fully evaluate effect modification. Combining data from a subset of our studies with extensive questions on usage also gave us the ability to evaluate characteristics of NSAID use which has been limited in past reviews. There was some variability among questions from different studies; in particular, we noticed two general patterns in how questions were asked. When the lead-in question included the definition of "regular use," the prevalence of NSAID use among controls was around 40\%; while broader questions reported a prevalence of around $70 \%$ among controls (Appendix A). Despite the two patterns of questions, results stratified by question type demonstrated consistently inverse associations. There were also some minor differences on how frequency of use was collected: open-ended vs. pre-determined responses, and what time period served as the reference period for estimating usage (Appendix A). Assuming the time period was representative of usual usage, we were able to define NSAID use in the same way across studies. Detailed individual-level data on known and suspected risk factors for EAC and EGJA were available for pooling from each study, thus allowing us to control for possible confounding from a standard set of risk factors across each study. There was some evidence of moderate heterogeneity between study populations; however, overall, there appears to be little evidence of heterogeneity across the majority of results except for duration of aspirin. Overall NSAID duration might have been overestimated, since we were unable to take into account potential concurrent use of aspirin and non-aspirin NSAIDs in the calculation. However, we re-evaluated overall NSAID duration taking into account concurrent use in two studies that collected sufficient data to carry out this analysis, and found that there was very little difference in study-specific estimates. Another limitation of our data is that no dosage information was collected in any of the studies. Inclusion of NSAID amounts would have provided a better indicator of drug exposure than frequency and duration alone. As most participating studies were case-control studies, data from these studies may be subject to biases; however, data from each study were obtained rapidly after enrollment and collected with detailed procedures. Results were also generally similar to those of the cohort study. Finally, we were unable to directly evaluate whether NSAID use varied by Barrett's esophagus status and whether this would have had an effect on reported associations, as the number of cases with information on Barrett's esophagus diagnosis ( $\mathrm{n}=93$ ) was not large enough to conduct any suitably powered analyses. However, with the small proportion of cancer cases with a prior Barrett's diagnosis, any effect on the overall results is likely to be small.

In summary, findings from this pooled analysis support the hypothesis that NSAID use provides potential benefits in preventing esophageal and esophagogastric adenocarcinomas. There is also evidence to suggest that increased frequency and longer duration of overall NSAID use is associated with further reduced risk of EAC, but these associations are not present when evaluated by NSAID type. Results from stratified analyses indicate that aspirin and non-aspirin NSAIDS have a similar effect on EAC risk overall. While the use of NSAIDs as a chemopreventive strategy is promising, the effectiveness of NSAIDs still has to be evaluated in randomized trials before this approach is advanced clinically.

\section{Supplementary Material}

Refer to Web version on PubMed Central for supplementary material. 


\section{Acknowledgments}

Grant Support: This work was supported in part by the Intramural Program of the National Institutes of Health (NIH). The US Multi-Center Study was funded by U01-CA57949 (awarded to T.L.V.), U01-CA57983 (awarded to M.D.G.), and U01-CA57923 (awarded to HA.R). The Los Angeles County Multi-ethnic Case-control Study was funded by 3RT-0122 ("Smoking and Risk of Proximal Vs. Distal Gastric Cancer," awarded to A.H.W.) and 10RT-0251 ("Smoking, microsatellite instability \& gastric cancers," awarded to A.H.W.) from the California Tobacco-Related Research Program and CA59636 (awarded to L.B.) from the National Cancer Institute. The Nova Scotia Barrett Esophagus Study was supported by the Nova Scotia Health Research Foundation ("Molecular mechanisms and lifestyle risk factor interactions in the pathogenesis of human esophageal adenocarcinoma," N419, to A.G.C.). The Factors Influencing the Barrett's Adenocarcinoma Relationship Study was funded by an IrelandNorthern Ireland Co-operation Research Project Grant sponsored by the Northern Ireland Research and Development Office, and the Health Research Board, Ireland (All-Ireland case-control study of Oesophageal Adenocarcinoma and Barrett's Oesophagus, awarded to L.J.M. and Harry Comber). The Australian Cancer Study was supported by the Queensland Cancer Fund and the National Health and Medical Research Council of Australia (Program no. 199600, awarded to D.C.W., Adele C. Green, Nicholas K. Hayward, Peter G. Parsons, David M. Purdie, and Penelope M. Webb). NIH-AARP was funded by the Intramural Program of the NIH.

\section{Appendix}

\section{Appendix A:}

\section{Individual study data used for pooled analysis}

\begin{tabular}{|c|c|c|c|c|}
\hline $\begin{array}{l}\text { Studies } \\
\text { included in this } \\
\text { analysis }\end{array}$ & Questions asked & Reference period & $\begin{array}{c}\text { Contributed data on } \\
\text { frequency of use of } \\
\text { aspirin, other NSAIDS } \\
\text { Precoded categories or } \\
\text { continuous }\end{array}$ & $\begin{array}{l}\text { Contributed data on } \\
\text { duration of use of aspirin, } \\
\text { other NSAIDS Precoded } \\
\text { categories or continuous }\end{array}$ \\
\hline $\begin{array}{l}\text { Los Angeles } \\
\text { County Multi- } \\
\text { Ethnic Study }\end{array}$ & $\begin{array}{l}\text { Have you ever } \\
\text { taken meds } \\
\text { regularly (at } \\
\text { least } 2 \text { times per } \\
\text { week for } 1 \\
\text { month or more) }\end{array}$ & 2 yrs before $\mathrm{dx}$ & Yes, continuous & Yes, continuous \\
\hline $\begin{array}{l}\text { United States } \\
\text { Multicenter } \\
\text { Study }\end{array}$ & $\begin{array}{l}\text { Before a year } \\
\text { ago, did you take } \\
\text { any of the meds } \\
\text { at least } 1 / \mathrm{wk} \text {, for } \\
6 \text { months or } \\
\text { longer? }\end{array}$ & $1 \mathrm{yr}$ before $\mathrm{dx}$ & Yes, continuous & Yes, continuous \\
\hline $\begin{array}{l}\text { Nova Scotia } \\
\text { Barrett } \\
\text { Esophagus } \\
\text { Study }\end{array}$ & $\begin{array}{l}\text { Have you ever } \\
\text { used any of the } \\
\text { following meds? }\end{array}$ & 5 yrs before $\mathrm{dx}$ & NSAIDs overall, continuous & NSAIDs overall, continuous \\
\hline $\begin{array}{l}\text { Australian Study } \\
\text { of Esophageal } \\
\text { Cancer }\end{array}$ & $\begin{array}{l}\text { How often have } \\
\text { you taken the } \\
\text { following meds } \\
\text { during the past } 5 \\
\text { years? }\end{array}$ & Past 5 yrs at entry & $\begin{array}{c}\text { Yes, categories } \\
\text { (Occasionally, <1/mo, 2-3x/ } \\
\text { mo, } 1 \mathrm{x} / \mathrm{wk}, 2-3 \mathrm{x} / \mathrm{wk}, 4-7 \mathrm{x} / \\
\text { wk, } 2 \text { or more } \mathrm{x} / \text { day })\end{array}$ & No \\
\hline $\begin{array}{l}\text { Factors } \\
\text { Influencing the } \\
\text { Barrett's/ } \\
\text { Adenocarcinoma } \\
\text { Relationship } \\
\text { Study }\end{array}$ & $\begin{array}{l}\text { Did you ever } \\
\text { take any of these } \\
\text { meds regularly } \\
\text { (at least } 1 / \text { wk for } \\
6 \text { mos or } \\
\text { longer)? }\end{array}$ & $1 \mathrm{yr}$ before $\mathrm{dx}$ & Yes, continuous & Yes, continuous \\
\hline $\begin{array}{l}\text { National } \\
\text { Institutes of } \\
\text { Health -AARP } \\
\text { Diet and Health } \\
\text { Study }\end{array}$ & $\begin{array}{l}\text { During the past } \\
12 \text { months, did } \\
\text { you take any of } \\
\text { the following } \\
\text { meds? }\end{array}$ & Past 1 yr at entry & $\begin{array}{c}\text { Yes, categories }(<2 \mathrm{x} / \mathrm{mo}, \\
2-3 \mathrm{x} / \mathrm{mo}, 1-2 \mathrm{x} / \mathrm{wk}, 3-4 \mathrm{x} / \mathrm{wk}, \\
4-5 \mathrm{x} / \mathrm{wk}, 1 \mathrm{x} / \mathrm{day}, 2 \text { or more } \\
\text { x/day })\end{array}$ & No \\
\hline
\end{tabular}




\section{References}

1. Steevens J, Botterweck AA, Dirx MJ, et al. Trends in incidence of oesophageal and stomach cancer subtypes in Europe. Eur J Gastroenterol Hepatol. 2010; 22:669-78. [PubMed: 19474750]

2. Cook MB, Chow WH, Devesa SS. Oesophageal cancer incidence in the United States by race, sex, and histologic type, 1977-2005. Br J Cancer. 2009; 101:855-9. [PubMed: 19672254]

3. Jemal A, Siegel R, Ward E, et al. Cancer statistics, 2009. CA Cancer J Clin. 2009; 59:225-49. [PubMed: 19474385]

4. Devesa SS, Blot WJ, Fraumeni JF Jr. Changing patterns in the incidence of esophageal and gastric carcinoma in the United States. Cancer. 1998; 83:2049-53. [PubMed: 9827707]

5. Corley DA, Kubo A. Influence of site classification on cancer incidence rates: an analysis of gastric cardia carcinomas. J Natl Cancer Inst. 2004; 96:1383-7. [PubMed: 15367571]

6. Vane JR. Inhibition of prostaglandin synthesis as a mechanism of action for aspirin-like drugs. Nat New Biol. 1971; 231:232-5. [PubMed: 5284360]

7. Whittle BJ, Higgs GA, Eakins KE, et al. Selective inhibition of prostaglandin production in inflammatory exudates and gastric mucosa. Nature. 1980; 284:271-3. [PubMed: 6767192]

8. Morris CD, Armstrong GR, Bigley G, et al. Cyclooxygenase-2 expression in the Barrett's metaplasia-dysplasia-adenocarcinoma sequence. Am J Gastroenterol. 2001; 96:990-6. [PubMed: 11316217]

9. Wilson KT, Fu S, Ramanujam KS, et al. Increased expression of inducible nitric oxide synthase and cyclooxygenase-2 in Barrett's esophagus and associated adenocarcinomas. Cancer Res. 1998; 58:2929-34. [PubMed: 9679948]

10. Buttar NS, Wang KK, Anderson MA, et al. The effect of selective cyclooxygenase-2 inhibition in Barrett's esophagus epithelium: an in vitro study. J Natl Cancer Inst. 2002; 94:422-9. [PubMed: 11904314]

11. Gupta RA, DuBois RN. Cyclooxygenase-2 inhibitor therapy for the prevention of esophageal adenocarcinoma in Barrett's esophagus. J Natl Cancer Inst. 2002; 94:406-7. [PubMed: 11904306]

12. Baguma-Nibasheka M, Barclay C, Li AW, et al. Selective cyclooxygenase-2 inhibition suppresses basic fibroblast growth factor expression in human esophageal adenocarcinoma. Mol Carcinog. 2007; 46:971-80. [PubMed: 17477358]

13. Lim HY, Joo HJ, Choi JH, et al. Increased expression of cyclooxygenase-2 protein in human gastric carcinoma. Clin Cancer Res. 2000; 6:519-25. [PubMed: 10690533]

14. Cho SJ, Kim N, Kim JS, et al. The anti-cancer effect of COX-2 inhibitors on gastric cancer cells. Dig Dis Sci. 2007; 52:1713-21. [PubMed: 17393325]

15. Jiang XH, Wong BC. Cyclooxygenase-2 inhibition and gastric cancer. Curr Pharm Des. 2003; 9:2281-8. [PubMed: 14529406]

16. Grau MV, Rees JR, Baron JA. Chemoprevention in gastrointestinal cancers: current status. Basic Clin Pharmacol Toxicol. 2006; 98:281-7. [PubMed: 16611203]

17. Baron JA, Sandler RS. Nonsteroidal anti-inflammatory drugs and cancer prevention. Annu Rev Med. 2000; 51:511-23. [PubMed: 10774479]

18. Ranka S, Gee JM, Johnson IT, et al. Non-steroidal anti-inflammatory drugs, lower oesophageal sphincter-relaxing drugs and oesophageal cancer. A case-control study Digestion. 2006; 74:109_ 15.

19. Vaughan TL, Dong LM, Blount PL, et al. Non-steroidal anti-inflammatory drugs and risk of neoplastic progression in Barrett's oesophagus: a prospective study. Lancet Oncol. 2005; 6:94552. [PubMed: 16321762]

20. Anderson LA, Johnston BT, Watson RG, et al. Nonsteroidal anti-inflammatory drugs and the esophageal inflammation-metaplasia-adenocarcinoma sequence. Cancer Res. 2006; 66:4975-82. [PubMed: 16651456]

21. Fortuny J, Johnson CC, Bohlke K, et al. Use of anti-inflammatory drugs and lower esophageal sphincter-relaxing drugs and risk of esophageal and gastric cancers. Clin Gastroenterol Hepatol. 2007; 5:1154-1159. e3. [PubMed: 17644046] 
22. Lindblad M, Lagergren J, Garcia Rodriguez LA. Nonsteroidal anti-inflammatory drugs and risk of esophageal and gastric cancer. Cancer Epidemiol Biomarkers Prev. 2005; 14:444-50. [PubMed: 15734971]

23. Akre K, Ekstrom AM, Signorello LB, et al. Aspirin and risk for gastric cancer: a population-based case-control study in Sweden. Br J Cancer. 2001; 84:965-8. [PubMed: 11286478]

24. Farrow DC, Vaughan TL, Hansten PD, et al. Use of aspirin and other nonsteroidal antiinflammatory drugs and risk of esophageal and gastric cancer. Cancer Epidemiol Biomarkers Prev. 1998; 7:97-102. [PubMed: 9488582]

25. Gammon MD, Terry MB, Arber N, et al. Nonsteroidal anti-inflammatory drug use associated with reduced incidence of adenocarcinomas of the esophagus and gastric cardia that overexpress cyclin D1: a population-based study. Cancer Epidemiol Biomarkers Prev. 2004; 13:34-9. [PubMed: 14744730]

26. Epplein M, Nomura AM, Wilkens LR, et al. Nonsteroidal antiinflammatory drugs and risk of gastric adenocarcinoma: the multiethnic cohort study. Am J Epidemiol. 2009; 170:507-14. [PubMed: 19584132]

27. Corley DA, Kerlikowske K, Verma R, et al. Protective association of aspirin/NSAIDs and esophageal cancer: a systematic review and meta-analysis. Gastroenterology. 2003; 124:47-56. [PubMed: 12512029]

28. Wang WH, Huang JQ, Zheng GF, et al. Non-steroidal anti-inflammatory drug use and the risk of gastric cancer: a systematic review and meta-analysis. J Natl Cancer Inst. 2003; 95:1784-91. [PubMed: 14652240]

29. Abnet CC, Freedman ND, Kamangar F, et al. Non-steroidal anti-inflammatory drugs and risk of gastric and oesophageal adenocarcinomas: results from a cohort study and a meta-analysis. $\mathrm{Br} \mathrm{J}$ Cancer. 2009; 100:551-7. [PubMed: 19156150]

30. Bosetti C, Gallus S, La Vecchia C. Aspirin and cancer risk: a summary review to 2007. Recent Results Cancer Res. 2009; 181:231-51. [PubMed: 19213573]

31. Tian W, Zhao Y, Liu S, et al. Meta-analysis on the relationship between nonsteroidal antiinflammatory drug use and gastric cancer. Eur J Cancer Prev. 2010; 19:288-98. [PubMed: 20386312]

32. Cook MB, Kamangar F, Whiteman DC, et al. Cigarette Smoking and Adenocarcinomas of the Esophagus and Esophagogastric Junction: A Pooled Analysis From the International BEACON Consortium. J Natl Cancer Inst. 2010; 102:1-10.

33. Sadeghi S, Bain CJ, Pandeya N, et al. Aspirin, nonsteroidal anti-inflammatory drugs, and the risks of cancers of the esophagus. Cancer Epidemiol Biomarkers Prev. 2008; 17:1169-78. [PubMed: 18483339]

34. Veugelers PJ, Porter GA, Guernsey DL, et al. Obesity and lifestyle risk factors for gastroesophageal reflux disease, Barrett esophagus and esophageal adenocarcinoma. Dis Esophagus. 2006; 19:321-8. [PubMed: 16984526]

35. Duan L, Wu AH, Sullivan-Halley J, et al. Nonsteroidal anti-inflammatory drugs and risk of esophageal and gastric adenocarcinomas in Los Angeles County. Cancer Epidemiol Biomarkers Prev. 2008; 17:126-34. [PubMed: 18187391]

36. Freedman ND, Murray LJ, Kamangar F, et al. Alcohol intake and risk of oesophageal adenocarcinoma: a pooled analysis from the BEACON Consortium. Gut. 2011; 60:1029-37. [PubMed: 21406386]

37. Higgins JP, Thompson SG, Deeks JJ, et al. Measuring inconsistency in meta-analyses. Bmj. 2003; 327:557-60. [PubMed: 12958120]

38. Nguyen DM, El-Serag HB, Henderson L, et al. Medication Usage and the Risk of Neoplasia in Patients With Barrett's Esophagus. Clin Gastroenterol Hepatol. 2009

39. Tsibouris P, Hendrickse MT, Isaacs PE. Daily use of non-steroidal anti-inflammatory drugs is less frequent in patients with Barrett's oesophagus who develop an oesophageal adenocarcinoma. Aliment Pharmacol Ther. 2004; 20:645-55. [PubMed: 15352913]

40. Nguyen DM, Richardson P, El-Serag HB. Medications (NSAIDs, statins, proton pump inhibitors) and the risk of esophageal adenocarcinoma in patients with Barrett's esophagus. Gastroenterology. 2010; 138:2260-6. [PubMed: 20188100] 
41. Rothwell PM, Fowkes FG, Belch JF, et al. Effect of daily aspirin on long-term risk of death due to cancer: analysis of individual patient data from randomised trials. Lancet. 2011; 377:31-41. [PubMed: 21144578]

42. Heath EI, Canto MI, Piantadosi S, et al. Secondary chemoprevention of Barrett's esophagus with celecoxib: results of a randomized trial. J Natl Cancer Inst. 2007; 99:545-57. [PubMed: 17405999]

43. Das D, Ishaq S, Harrison R, et al. Management of Barrett's esophagus in the UK: overtreated and underbiopsied but improved by the introduction of a national randomized trial. Am $\mathrm{J}$ Gastroenterol. 2008; 103:1079-89. [PubMed: 18445097]

44. Husain SS, Szabo IL, Tamawski AS. NSAID inhibition of GI cancer growth: clinical implications and molecular mechanisms of action. Am J Gastroenterol. 2002; 97:542-53. [PubMed: 11922545]

45. Thun MJ, Henley SJ, Patrono C. Nonsteroidal anti-inflammatory drugs as anticancer agents: mechanistic, pharmacologic, and clinical issues. J Natl Cancer Inst. 2002; 94:252-66. [PubMed: 11854387]

\section{Abbreviations}

BEACON

BMI

CI

EAC

EGJA

NSAIDs

OR
Barrett's Esophagus and Esophageal Adenocarcinoma Consortium

body mass index

confidence interval

esophageal adenocarcinoma

esophagogastric junctional adenocarcinoma

non-steroidal anti-inflammatory drugs

odds ratio 


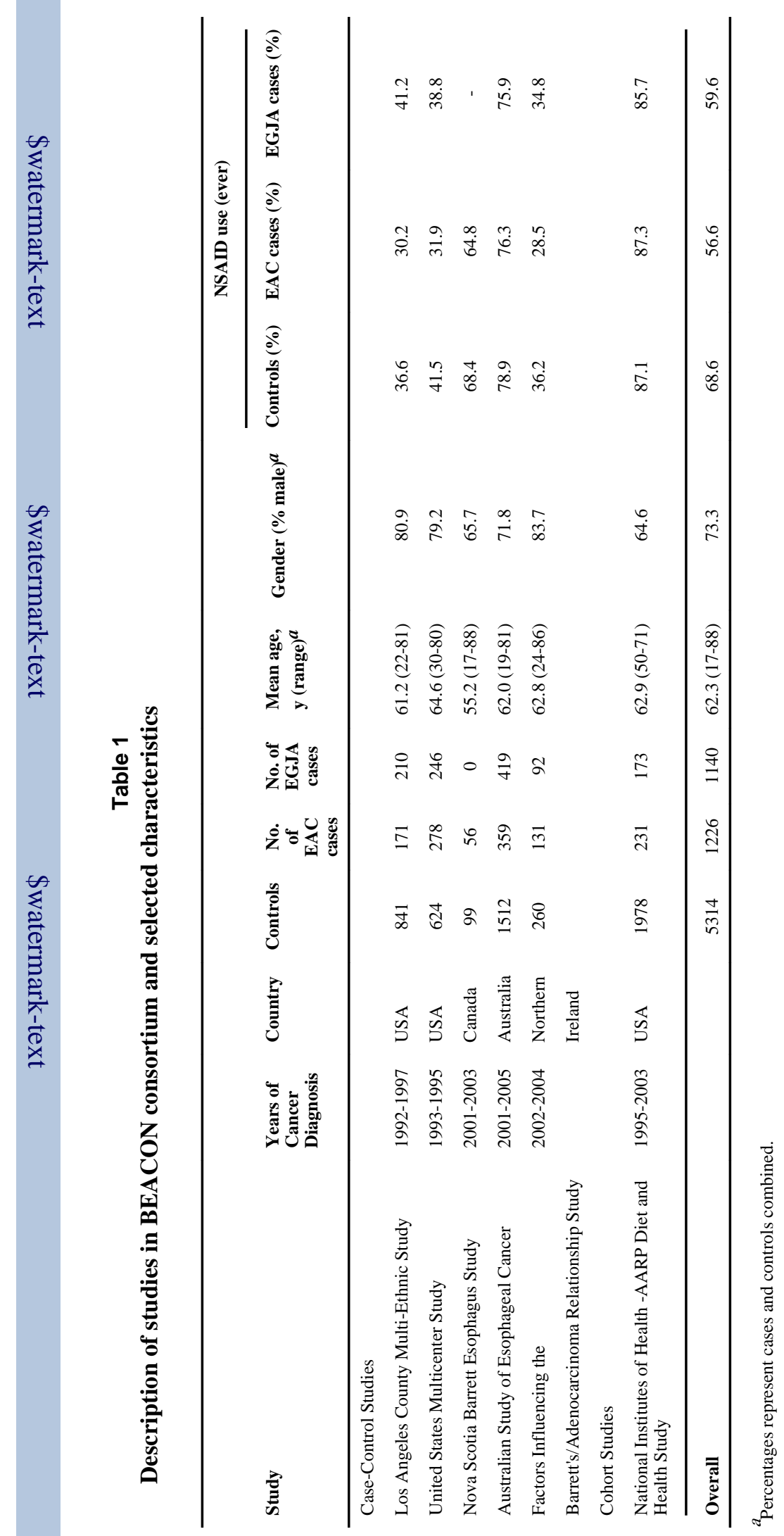




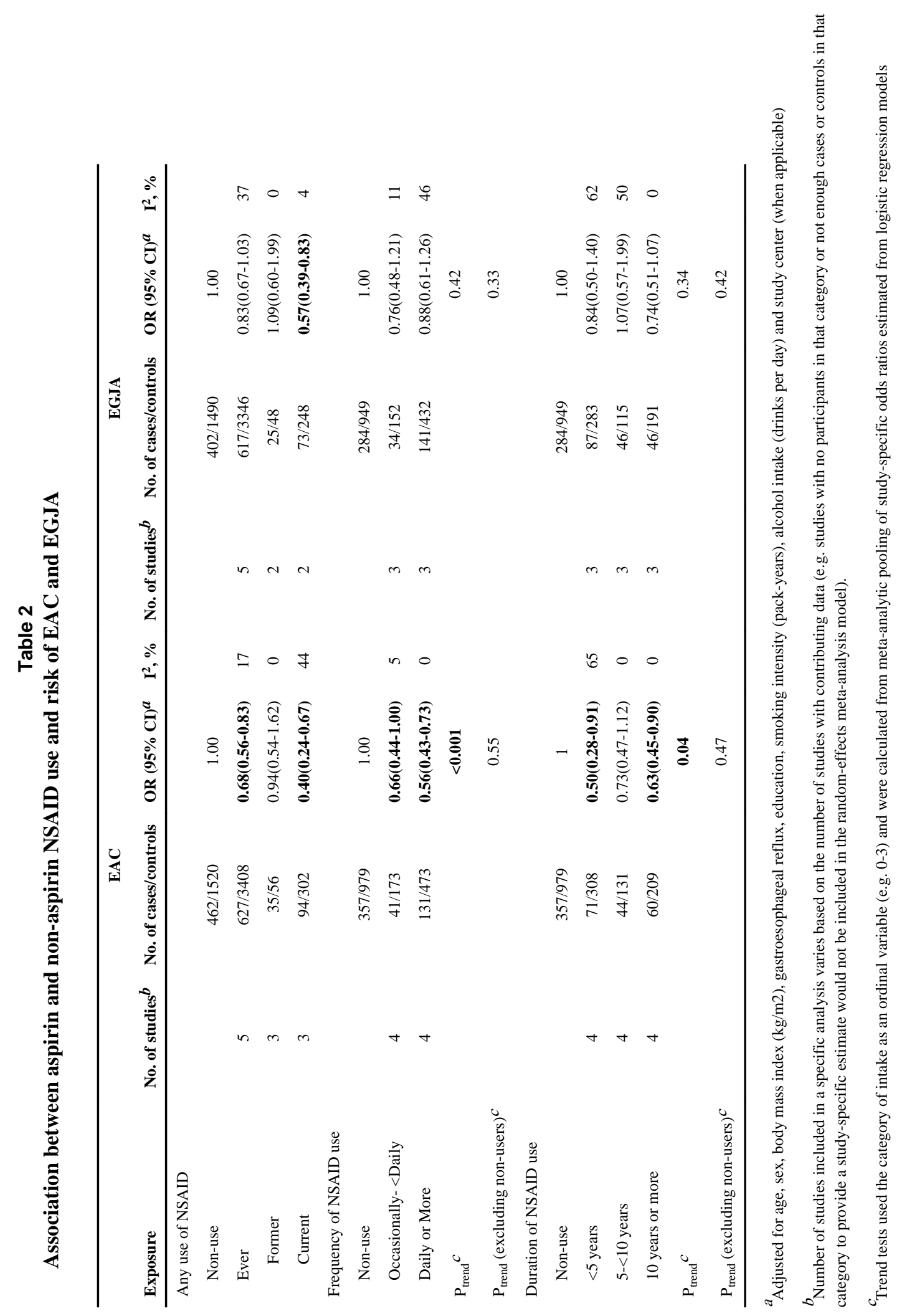




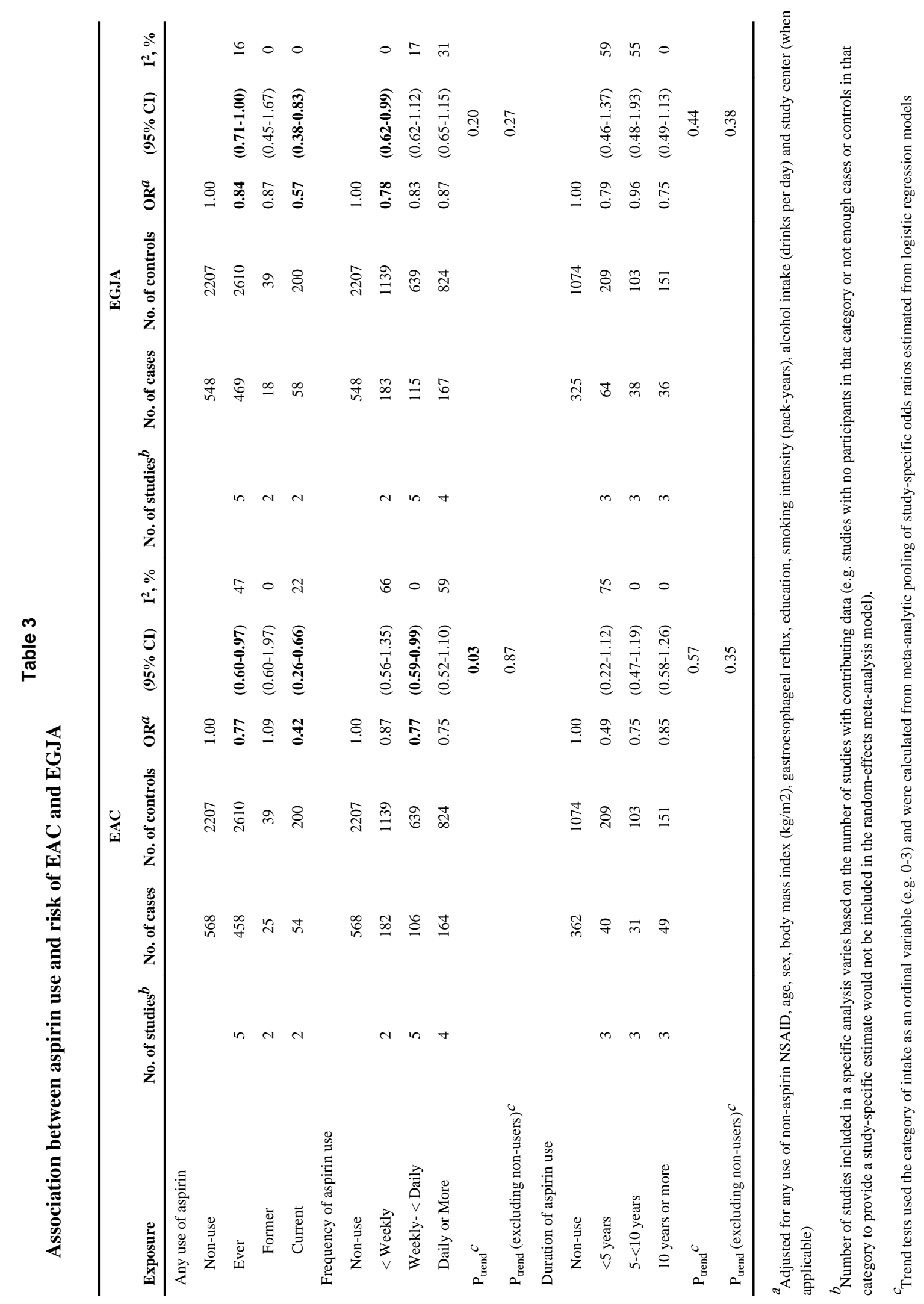









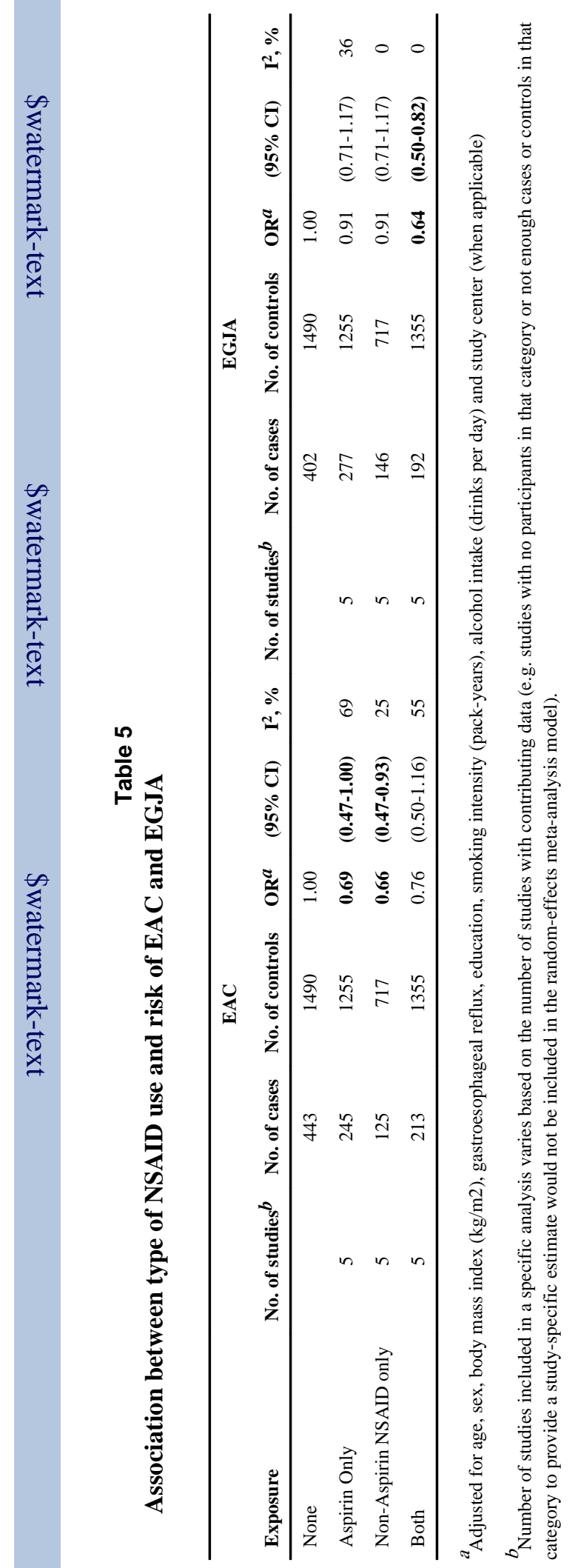

Gastroenterology. Author manuscript; available in PMC 2013 March 01. 